\title{
Effectiveness of Mother Steered Essential Preemies Care Bundle on The Level of Anxiety Among Mothers of Preemies
}

ISSN: 2576-9200

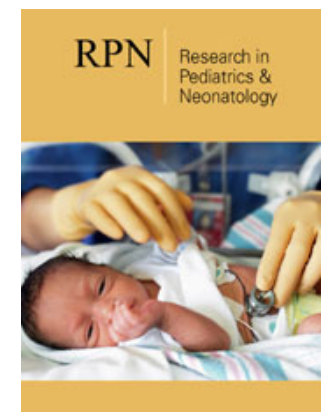

*Corresponding author: Jayanthi P, CoGuide \& Professor, Shri Sathya Sai College of Nursing, Tamil Nadu, India

Submission: 酸 October 26, 2020

Published: 剕 November 16, 2020

Volume 5 - Issue 1

How to cite this article: Hemamalini J, Jaya N, Jayanthi P. Effectiveness of Mother Steered Essential Preemies Care Bundle on The Level of Anxiety Among Mothers of Preemies. Research in Pediatrics \& Neonatology. 5(1). RPN. 000604. 2020. DOI: $10.31031 /$ RPN.2020.05.000604

Copyright $\subset$ Jayanthi $P$. This article is distributed under the terms of the Creative Commons Attribution 4.0 International License, which permits unrestricted use and redistribution provided that the original author and source are credited.

\section{Hemamalini $J^{1}$, Jaya $\mathrm{N}^{2}$ and Jayanthi $\mathrm{P}^{3 *}$}

${ }^{1}$ PhD scholar, Omayal Achi College of Nursing affiliated to The Tamil Nadu Dr. MGR Medical University, Chennai, Tamil Nadu, India

${ }^{2}$ Research Guide \& Professor, Shenbaga College of Nursing affiliated to The Tamil Nadu Dr. MGR Medical University, Chennai, Tamil Nadu, and India

${ }^{3}$ Co-Guide \& Professor, Shri Sathya Sai College of Nursing, Tamil Nadu, India

\begin{abstract}
Background: The birth of a baby prior to the expected date of its arrival to this world is associated with the emotions, feelings of anxiety, fear over danger, infrequent access and interaction with the infant during the period of hospitalization in the Neonatal Intensive Care Unit.
\end{abstract}

Aim and objective: The objective of the study was to assess the effectiveness of a Mother Steered Essential Preemies Care Bundle on the level of anxiety among mothers of preemies.

Methodology: A quantitative research approach with quasi-experimental study was adopted. Atotal of 240 mothers of preemies (120 each in the experimental and control group) participated in the study. Non-probability purposive sampling technique was used to select the subjects. Data was collected using Modified Perinatal Anxiety Screening Scale.

Result: Comparison of the level of anxiety based on the statistics revealed that the ' $\mathrm{t}$ ' value for anxiety in the experimental group was 10.83 . This has shown a very high statistical significance at $p \leq 0.001$.

Conclusion: The Mother Steered Essential Preemies Care Bundle was effective in significantly reducing the anxiety of mothers of preemies.

Keywords: Preemies care bundle; anxiety of mothers of preemies

\section{Introduction}

Globally, 15 million babies are born preterm every year and this number is in increasing trend. Combined with low birth weight among infants, preterm birth causes a global and alarming problem contributing to neonatal morbidity and mortality at high level. Preterm birth complications are the leading cause of death among children under 5 years of age. Three quarters of them could be saved with current and cost effective interventions [1]. Untimed birth of an infant or giving birth to an unhealthy one is a panic situation linked with parental anxiety and other psychological glitches. Admission of a neonate to the intensive care unit would be unexpected and nervous for their mothers [2]. Salah M et al. [3] have found 50.8\% of mothers of preterm and low birth weight infants admitted in the NICU in Gaza Strip of Palestine had severe to very severe symptoms of anxiety, $38.5 \%$ of mothers had severe to very severe symptoms of depression. Hospitalizing the newborn is a key stressful event for all the relations especially the mother. It is a life changing junction in the emotional, personal and social life fronts for most of the mothers who changes themselves in the manner they sight themselves, their relationship with life mates and their position in the family [3].

Birth prior to the full term causes psychological effects when compared to term pregnancy. A mother gets her opportunity for adapting to her part in parenting, the physiological changes when her infant born at the estimated time of birth. Whereas, advancement of events of birth, parenting and unexpected hospitalization of the new dear one do not provide such opportunity for the mother to adapt to the situation. Involving parents in caring of premature baby is the most effective approach to counter this problem. Parental participation in care of preemies springs a good bondage and self-reliance especially to the mother which aids in speeding the discharge from the hospital, ultimately resulting in saving the purse of the parent, exposure to infections in hospital [4]. Mothers of preterm neonates experience significant anxiety and 
depression during the immediate postnatal period and kangaroo mother care can reduce their stress [5]. Meeting the needs and caring of a premature baby in a family is a thumbs up assignment to the family members. Parental pressure is identified with anxiety and stresses over the new-born are wellbeing, changing to the child rearing job and sentiments of despondency concerning the loss of a normal child. Giving birth to a preterm or unhealthy baby is a troubling and awful situation for the parents and they need concentration with reference to their needs for continuity of care for preemie, follow up and information about the preemies care [6].

The mothers who give birth to a baby before completion of the gestation lead to beginning of her parenting in unfamiliar and shuddery surroundings of the NICU. Hospitalization of the neonate for a longer period results in family members; mothers in particular, feel they are isolated from their babies and their emotions turns into stress. Intervention to the mothers in the form of educational information and psychological support were proved to be effective in reducing the maternal psychological problems in the NICU [7]. Performing proper orientation for the parents of the preemies, especially mothers, will help them familiarize with the NICU environment. Ultimately, such orientation will result decreasing the anxiety of parents [8]. Mothers who give birth to a preterm baby would be anxious about such delivery and fear over the infant mortality and loss of joyful interaction with their babies. They expressed their worries about the regularity and time duration of their interaction with their babies during hospitalization in NICU. The mothers may need supportive person to pass through such hard-hitting situation. Understanding the experience of mothers of preemies in such dreadful setting is a vital step to distinguish their needs and address them successfully. The challenges faced by mothers, particularly, inadequate information on preemies care and emotional demands, needs to be addressed. Involving mothers by sharing of information, educating them on preemies care and hospital policies is essential. Supporting them in breastfeeding and kangaroo mother care would empower them and promote their physical and psychological well-being [4]. Early mental health screening may help the mothers of late preterm infants to get rid of anxiety [9]. Intervention to the mothers with the aim of reducing the anxiety and stress level of mothers is needed to prevent them at the initial stage itself [10]. Hence, the investigator felt a study needs to be done whether a comprehensive bundle of interventions would have an impact in reducing the anxiety level of the mothers of preemies.

\section{Statement of the problem}

A quasi-experimental study to assess the effectiveness of the Mother Steered Essential Preemies Care Bundle on the level of anxiety among mothers of preemies admitted at selected hospitals in Chennai.

\section{Objectives}

a. To assess the effectiveness of Mother Steered Essential Preemies Care Bundle on the level of anxiety among mothers of preemies. b. To associate the selected demographic variables with the mean differed level of anxiety among mothers in the experimental and control groups.

\section{Null hypotheses}

$\mathbf{N H}_{\mathbf{1}}$ : There is no significant difference in the pre and posttest level of anxiety among mothers of preemies between experimental and control group.

$\mathbf{N H}_{2}$ : There is no significant association between the selected demographic variables with the mean differed level of anxiety among mothers in the experimental and control group.

\section{Materials and Methods}

The researcher adopted a quantitative research approach and quasi-experimental research design for this study. Government Children Hospital was chosen for setting of the study. Investigator conducted the study by selecting 240 mothers (120 each in experimental and control group) using Purposive Sampling technique. Data collection tool consist of demographic variables, background variables of mothers and modified perinatal anxiety screening scale (m-pass). Was used to assess the anxiety of mothers. The intervention tool prepared by the investigator that is the Mother Steered Essential Preemies Care Bundle which comprised of Education-Video assisted teaching on orienting mothers to Neonatal Intensive Care Unit (NICU) setup and on preemies for 15-20 minutes for small group of mothers. Demonstration - Using newborn and breast dummy, demonstration for the procedures of preemies care for a small group of mothers for a period of 40-45 minutes. Return demonstration by the mothers using dummies at the end of the session. Pamphlet was given regarding preemies care to experimental mothers. Body mind wellness was used to recycling of negative thoughts into positive thoughts for a period of 5-10 minutes. The study was ethically approved by International Centre for Collaborative Research. Informed consent was obtained from the mothers. The hospital routine was followed for the control group.

After getting informed consent, the demographic data of mothers was collected and pre test level of anxiety of the mothers of preemies in both the experimental and control groups was assessed using modified perinatal anxiety screening scale. Then, the investigator had taught the mothers of preemies in the experimental group through video for 20 minutes. On the next day, demonstration was done for the procedures for a small group of 3 to 5 mothers of preemies in the experimental group for a period of 25 - 30 minutes using newborn and breast dummy; body mind wellness approach was taught to the mothers in the experimental group for 5-10 minutes. Subjects were given pamphlet on care of preemies. Post-test on anxiety was assessed on the $7^{\text {th }}$ day of intervention. Data was analysed using descriptive statistics such as mean, standard deviation and inferential statistics such as chi square test, repeated ANOVA paired t-test and student independent t-test. 


\section{Result}

$39.2 \%$ and $31.7 \%$ of mothers were aged between 21 and 30 years, 33.3 and $25.38 \%$ of mothers completed Middle School education 95.95 and 99.25 of mothers were not employed, $81.7 \%$ and $76.7 \%$ had $<5$ years of marital life, $43.3 \%$ and $47.5 \%$ of mothers resided in rural area, $75.5 \%, 81.7 \%$ of mothers in both the groups haven't received any information regarding preemies. in experimental and control group respectively. Anxiety reduction level of elder mothers 16.89 SD (14.00), more educated mothers 12.20 $\mathrm{SD}(10.68)$ and mothers with less duration of marital life 17.56 SD(14.57), residing in urban area 18.05 SD( 16.64), of mothers anxiety has reduced than others. There was a high and very high level of significance at $p \leq 0.01$ and $p \leq 0.001$ respectively with the reduction score when computed using one-way ANOVA $\mathrm{F}$ test / $\mathrm{t}$ test. All these statistical analysis indicates that mother steered essential preemies care bundle especially body mind wellness approach was effective in reducing the level of anxiety among mothers in the experimental group when compared with the control group.

\section{Discussion}

The aim of this study was to assess the effectiveness of Mother Steered Essential Preemies Care Bundle on the level of anxiety among mothers. With regard to selected background variables of the mothers, most of the women, $74.2 \%$ and $77.5 \%$, don't have the family medical and obstetrical history in the experimental and control group respectively. $75 \%$ and $81.7 \%$ of the mothers in the experimental and control group respectively hadn't received any information regarding preemies care and $53.3 \%$ and $59.1 \%$ of mothers of preemies in both groups respectively gained information through friends or relatives. $97.5 \%$ and $99.2 \%$ of mothers in both the groups respectively were not exposed to handling of preemies. Most of the mothers in both the groups had mother as a supporting person to take care of their preemies.

The present study findings were consistent with the findings of studies done by Salah M, et al. [3] found that $24.6 \%$ of the mothers were primi parous. Subhashini L, et al. [11] revealed that majority of the mothers (86.6\%) were under 25 years. Aldirawi A, et al. [12] found that most of the mothers (46.7\%) fell under the age group 20-30 years and (49.28\%) resided in one particular location (Middle area); $50 \%$ of surveyed mothers had a secondary education level of education. Ontita MK, et al. [13] found that the age range of majority of the mothers was 19-35 years, (56.7\%) had secondary school as the highest level of education. The data findings in Table 1 presented the Pre-test and post-test percentage of anxiety reduction score in both groups. In experimental group, Pre-test, anxiety score was $54.96 \%$ and in post-test it was reduced to $33.93 \%$, so the percentage of reduction after intervention was $21.03 \%$. In control group, pre-test anxiety score was $55.60 \%$ and in post-test it was $54.96 \%$ so the percentage of reduction after routine care was $0.64 \%$.

Table 1: Domain wise pre and posttest level of anxiety scores among mothers of preemies in the experimental and control group. $\mathrm{N}=240$

\begin{tabular}{|c|c|c|c|c|c|c|c|}
\hline \multirow{2}{*}{ S. No. } & \multirow{2}{*}{ Domains } & \multicolumn{3}{|c|}{ Group } \\
\cline { 3 - 8 } & & \multicolumn{3}{|c|}{ Experimental (n=120) } & \multicolumn{4}{c|}{ Control (n=120) } \\
\cline { 3 - 8 } & & Pre-test \% & Post-test \% & \% of reduction score & Pre-test \% & Post-test \% & \% of reduction score \\
\hline 1 & Excessive Worry and Specific Fears & 66.8 & 41.9 & 24.8 & 67.6 & 67.2 & 0.3 \\
\hline 2 & Perfectionism, Control and Trauma & 54.8 & 32.6 & 22.1 & 57.4 & 56.6 & 0.7 \\
\hline 3 & Social Anxiety & 45.7 & 34.2 & 11.5 & 43.7 & 43.1 & 57 \\
\hline 4 & Acute Anxiety and Adjustment & 55.3 & 28.4 & 26.9 & 57.7 & 34.5 & 0.7 \\
\hline 5 & Physiological Changes & 37.5 & 27.2 & 10.3 & 35.2 & 34.5 \\
\hline & Overall & $\mathbf{5 4 . 9}$ & $\mathbf{3 3 . 9}$ & $\mathbf{2 1}$ & $\mathbf{5 5 . 6}$ & $\mathbf{5 4 . 9}$ & $\mathbf{0 . 6}$ \\
\hline
\end{tabular}

Table 2: Level of pre and posttest anxiety score among mothers of preemies in the experimental and control group. $\mathrm{N}=240$

\begin{tabular}{|c|c|c|c|c|c|}
\hline & \multirow{3}{*}{ Level of Anxiety } & \multicolumn{4}{|c|}{ Group } \\
\hline & & \multicolumn{2}{|c|}{ Experimental $(n=120)$} & \multicolumn{2}{|c|}{ Control $(n=120)$} \\
\hline & & $\mathbf{n}$ & $\%$ & $\mathbf{n}$ & $\%$ \\
\hline \multirow{3}{*}{ Pre test } & Mild & 21 & 17.5 & 18 & 15 \\
\hline & Moderate & 99 & 82.5 & 102 & 85 \\
\hline & High & 0 & 0 & 0 & 0 \\
\hline \multirow{3}{*}{ Post test } & Mild & 66 & 55 & 23 & 19.2 \\
\hline & Moderate & 54 & 45 & 97 & 80.8 \\
\hline & High & 0 & 0 & 0 & 0 \\
\hline
\end{tabular}


Table 3: Comparison of posttest level of anxiety among mothers of preemies between experimental and control group. $\mathrm{N}=240,{ }^{* *}$ Highly significant at $\mathrm{P} \leq 0.01,{ }^{* * *}$ Very highly significant at $\mathrm{P} \leq 0.001$.

\begin{tabular}{|c|c|c|c|c|c|c|c|}
\hline \multirow{3}{*}{ S. No. } & \multirow{3}{*}{ Domains } & \multicolumn{4}{|c|}{ Group } & \multirow{3}{*}{ Mean difference } & \multirow{3}{*}{$\begin{array}{c}\text { Student Independent } \\
\text { t-Test }\end{array}$} \\
\hline & & \multicolumn{2}{|c|}{ Experimental $(n=120)$} & \multicolumn{2}{|c|}{ Control $(n=120)$} & & \\
\hline & & Mean & SD & Mean & SD & & \\
\hline 1 & Excessive Worry and Specific Fears & 10.07 & 4.67 & 16.14 & 2.69 & 6.07 & $\mathrm{t}=12.34 \mathrm{p}=0.001^{* * *}(\mathrm{~S})$ \\
\hline 2 & Perfectionism, Control and Trauma & 3.92 & 3.38 & 6.8 & 1.87 & 2.88 & $\mathrm{t}=8.18 \mathrm{p}=0.001^{* * *}(\mathrm{~S})$ \\
\hline 3 & Social Anxiety & 3.08 & 2.39 & 3.88 & 1.53 & 0.8 & $\mathrm{t}=3.09 \mathrm{p}=0.01^{* *}(\mathrm{~S})$ \\
\hline 4 & Acute Anxiety and Adjustment & 5.12 & 3.45 & 10.27 & 2.3 & 5.15 & $\mathrm{t}=13.62 \mathrm{p}=0.001^{* * *}(\mathrm{~S})$ \\
\hline \multirow[t]{2}{*}{5} & Physiological Changes & 3.27 & 2.49 & 4.14 & 1.04 & 0.87 & $\mathrm{t}=3.52 \mathrm{p}=0.01^{* *}(\mathrm{~S})$ \\
\hline & Overall & 25.45 & 15.05 & 41.22 & 5.3 & 15.77 & $\mathrm{t}=10.83 \mathrm{p}=0.001^{* * *}(\mathrm{~S})$ \\
\hline
\end{tabular}

The data findings in Table 2 presented the pre-test and posttest anxiety score among mothers of preemies. The post test results showed that there was a reduction in the level of anxiety Figure 1. In the post test, it was reduced to $45 \%$ in the experimental group; but, it was reduced to $80.8 \%$ only in the control group from $82.5 \%$ and $85 \%$ respectively. The present study findings were found to be consistent with the research findings put forward by Damanabad $\mathrm{ZH}$, et al. [14] who found out that $62 \%(n=100)$ of mothers had moderate level of state anxiety and 54\% (n=100) had moderate level of trait anxiety. The data findings in Table 3 presented the posttest level of anxiety score among mothers of preemies between the experimental and control groups. The base line anxiety score in the pre-test was 41.22 and the post-test anxiety score was 25.45 after the intervention and mean difference in anxiety score was 15.77 in the experimental group shows highly significant at $\mathrm{P} \leq 0.01$, very highly significant at $\mathrm{P} \leq 0.001$

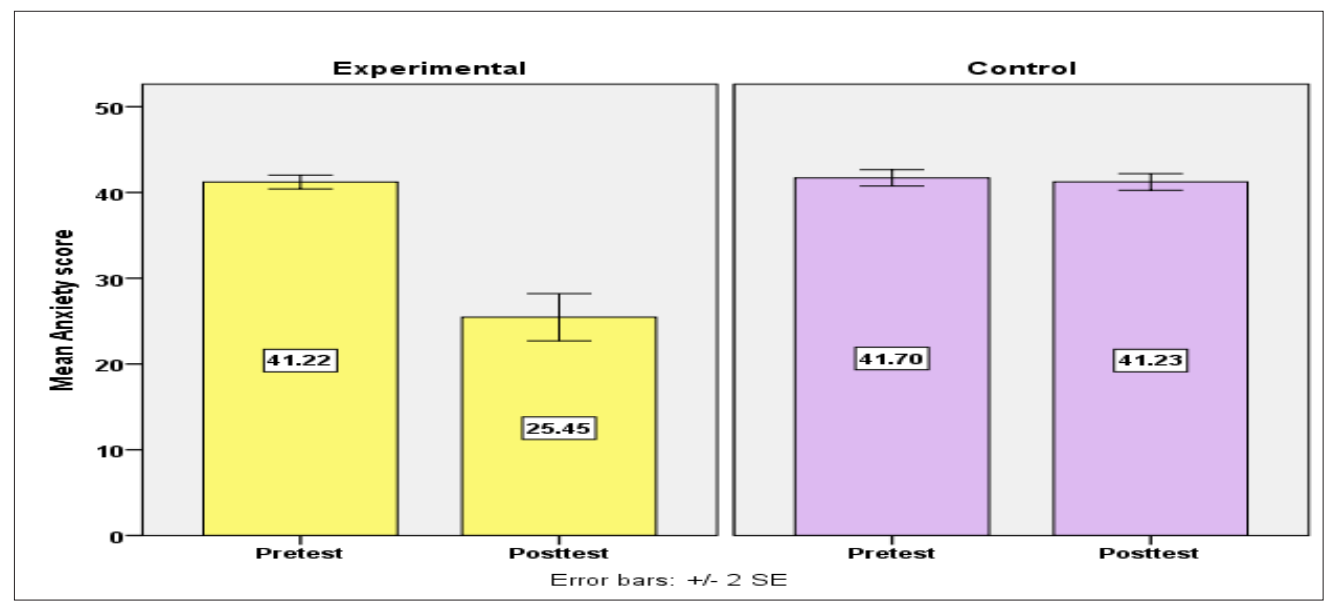

Figure 1: Comparison of pre and posttest mean anxiety score between experimental and control group N=240.

The present study findings were found to be consistent with the research findings put forward by Koochaki M, et al. [15] found that the anxiety score before the intervention was 19.45 and reduced to 11.52 after the intervention in experimental group. Whereas, in the control group, the pre-test score was 20.67 and reduced to 8.95 in the post test. The comparison within and between the experimental and control groups showed that there was a statistical significance, indicating that the Mother Steered Essential Preemies Care Bundle and the overall plan was effective, feasible and practicable to be applied. The association of the selected demographic, background variables of mothers with the mean differed level of anxiety was analysed using one way ANOVA F- test/student independent t-test revealed that there was a statistically significant association of the mean differed anxiety score at $p \leq 0.01$ and $p \leq 0.001$ with demographic variables, namely, age, educational status, years of marital life, menstrual cycle, area of residence, family medical and obstetrical history, previous information on preemies care. Anxiety score of elder mothers, more educated mothers and mothers with less duration of marital life, mothers having regular menstrual cycle, mothers reside in urban area, mothers with no family medical and obstetrical history and mothers have no previous of information on preemies care were reduced more than others.

\section{Conclusion}

The study on the effectiveness of Mother Steered Essential Preemies Care Bundle was effective, low cost, easy to administer, 
very useful in significantly reducing the level of anxiety among mothers of preemies. Hence, the study recommended the utilization of the mothers steered essential preemies care bundle in the various hospitals and in the community. It can also be used by nurse researchers, nurse administrators, nurse educators and other health care professionals to reduce the anxiety level among mothers hence it fetches worthy model bundle which offers goodness in mothers and preemies.

\section{Acknowledgements}

My sincere thanks to all content validity experts from various institutions and all the mothers who participated in my study and to Somerville S, Byrne SL, the authors of the Perinatal Anxiety Screening Scale.

\section{References}

1. WHO (2012) Born too soon: The global action report on preterm birth.

2. John HB, Philip RM, Santhanam S, Padankatti SM, Sebastian T, et al. (2018) Activity based group therapy reduces maternal anxiety in the neonatal intensive care unit-a prospective cohort study. Early Hum Dev 123: $17-21$.

3. Salah M, Breaka R, Alkasseh A (2018) Prevalence of anxiety and depression among mothers of newborns admitted to neonatal intensive care units in Gaza strip. Psychiatry Open Access, Edelweiss 2(1): 10-4.

4. Lomotey AY, Bam V, Diji AK, Asante E, Asante HB, et al. (2020) Experiences of mothers with preterm babies at a mother and baby unit of a tertiary hospital: A descriptive phenomenological study. Nursing Open 7(1): 150-159.

5. Rao P, Raajashri R, Bethou A, Bhat V, Palanivel C (2019) Does kangaroo mother care reduce anxiety in postnatal mothers of preterm babies?-a descriptive study from a tertiary care centre in south India. J Nepal Health Res Counc 17(1): 42-45.

6. Hagen IH, Iversen VC, Nesset E, Orner R, Svindseth MF (2019) Parental satisfaction with neonatal intensive care units: A quantitative cross- sectional study. BMC Health Serv Res 19(1): 37.

7. Ong SL, Abdullah KL, Danaee M, Soh KL, Soh KG, et al. (2019) The effectiveness of a structured nursing intervention program on maternal stress and ability among mothers of premature infants in a neonatal intensive care unit. J Clin Nurs 28(3-4): 641-649.

8. Abeasi DA, Emelife B (2020) What mothers go through when the unexpected happens: A look at challenges of mothers with preterm babies during hospitalization in a tertiary institution in Nigeria. Journal of Nursing and Midwifery Sciences 7(1): 22-29.

9. Tully KP, Davis DH, Silva S, Brandon D (2017) The relationship between infant feeding outcomes and maternal emotional well-being among mothers of late preterm and term infants: A secondary, exploratory analysis. Adv Neonatal Care 17(1): 65-75.

10. Ong SL, Abdullah KL, Danaee M, Soh KL, Soh KG, et al. (2019) Stress and anxiety among mothers of premature infants in a Malaysian neonatal intensive care unit. J Reprod Infant Psychol 37(2): 193-205.

11. Subhashini L, Radha MS, Baby GK (2016) Mothers perception of health care needs of preterm neonates in intensive care unit. Journal of Clinical and Biomedical Sciences 6(2): 59-62.

12. Aldirawi A, Khateeb AE, Mustafa AA, Abuzerr S (2019) Mothers knowledge of health caring for premature infants after discharge from neonatal intensive care units in the Gaza strip, Palestine. Open Journal of Pediatrics 9(3): 239-252.

13. Ontita MK, Abong GO, Mwangi AM, Andago AA (2016) Knowledge and practice of essential care among preterm and low birth weight infants in Kenyatta national hospital, Nairobi, Kenya. Journal of International Academic Research for Multidisciplinary. 4(8): 2320-5083.

14. Damanabad ZH, Valizadeh L, Arani MM, Hosseini M, Jafarabadi MA, et al. (2019) Evaluation of maternal anxiety in mothers of infants admitted to the neonatal intensive care unit. International Journal of Paediatrics $7(10)$ : 10215-10224.

15. Koochaki M, Mahmoodi Z, Saeieh SE, Kabir K, Tehranizadeh M, et al. (2017) The effect of cognitive-behavioral counseling on anxiety in the mothers of infants in the NICU: A randomized controlled trial. F1000Res 6: 1679 . 